\title{
Multi-modality imaging of referred civilian combat-related injuries: a multi-center study in Egypt
}

\author{
Marie Nader Grace, Iman Mohamed Hamdy Ibrahim and Sally Fouad Tadros * (1)
}

\begin{abstract}
Background: Several Arab countries as well as many parts of the world are currently involved in armed conflicts. Characterization and documentation of combat-related injury patterns and their impact on healthcare are a difficult challenge. However, it is crucial in planning and developing of strategies capable of addressing the demands of illequipped medical facilities. The aim of this study was to record the different patterns of combat-related injuries sustained by civilians transferred to Egyptian tertiary hospitals for further investigation and definite treatment after primary stabilization by an emergency trauma team in their countries.

Results: Metallic foreign bodies were detected in different body locations in $49.1 \%$ of patients, while bullets were identified in 12.3\%. Injuries involving the musculoskeletal system of the extremities were the most frequent (77.2\%), followed in descending order by maxillofacial injuries (41\%), thoracic injuries (32.1\%), cranial injuries (31\%), abdominal injuries (21.1\%), spinal injuries (8.8\%), and vascular injuries (4.7\%). Among the extremities injuries, bone fractures were the most common (68.5\%).

Conclusion: Radiological assessment aids in the evaluation of patients coming from conflict zones pre- and postoperatively, to recognize the precise sites and types of their injuries, the number and location of metallic shrapnel or bullets, and detection of possible associated complications, which aid in accurate demonstration of the extent and patterns of combatrelated injuries and guide the management plan.
\end{abstract}

Keywords: Combat zones, Gunshot wounds, Missile injuries

\section{Background}

Several Arab countries as well as many parts of the world are currently involved in armed conflicts. War causalities impose a substantial burden on healthcare systems, especially in developing countries, because of resources constraints and scarcity of highly trained medical personnel. Characterization and documentation of armed conflict injury patterns and their impact on healthcare are difficult challenges. However, it is crucial in planning and developing of strategies capable of addressing the demands of illequipped medical facilities $[1,2]$.

\footnotetext{
* Correspondence: sallyfouad86@gmail.com

Faculty of Medicine, Cairo University, Kasr Al-Ainy Faculty of Medicine, Al-Manial, Cairo 11559, Egypt
}

Trauma is the most eminent health risk in war-time. The Arab world's ongoing conflicts are marked by military engagement in civilian centers making civilians more susceptible to injury [2].

Combat-related trauma injuries incorporate blast injuries and gunshot wounds. Blast injuries compromise any injury caused by an explosion; they are usually severe inducing serious morbidities with a high mortality rate. Gunshot wounds are inflicted by the discharge of a loaded weapon, most commonly, firearms [3].

The management of combat-related injuries is an immensely complicated job. Many countries in the Arab world lack the proper facilities to treat such injuries, and so, patients are transferred to neighboring countries to receive the necessary medical care [3].

\section{Springer Open}

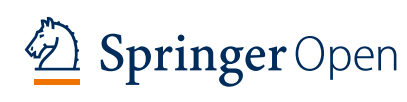

(C) The Author(s). 2021 Open Access This article is licensed under a Creative Commons Attribution 4.0 International License, which permits use, sharing, adaptation, distribution and reproduction in any medium or format, as long as you give appropriate credit to the original author(s) and the source, provide a link to the Creative Commons licence, and indicate if changes were made. The images or other third party material in this article are included in the article's Creative Commons licence, unless indicated otherwise in a credit line to the material. If material is not included in the article's Creative Commons licence and your intended use is not permitted by statutory regulation or exceeds the permitted use, you will need to obtain permission directly from the copyright holder. To view a copy of this licence, visit http://creativecommons.org/licenses/by/4.0/. 
The aim of this study was to record the different patterns of combat-related injuries sustained by civilians transferred to the Egyptian tertiary hospitals for further investigation and definite treatment after primary stabilization by an emergency trauma team in their countries.

\section{Methods}

\section{Study population}

Local institutional review board approval was granted before conducting this case series study, and written informed consent was obtained from all patients or their authorized representatives.

We included all 171 consecutive civilian patients suffering from combat-related injuries caused by bombs blast or gunshots, transferred to Egypt after primary stabilization by an emergency trauma team at their countries, admitted to 3 Egyptian multi-specialty tertiary-care hospitals during the period from March 2019 to September 2019, and referred to the Radiology Department to assess the pattern and full extent of their injuries before receiving definitive treatment. One hundred six patients were included from one hospital, 58 patients from another hospital, and 7 patients from the third hospital. All were males with an age range of $19-83$ years and a mean age of 28.9 years.

\section{Imaging techniques}

Patients were scanned with the following scanners: Siemens Somatom Definition Flash CT 256 slice, Philips Ingenuity CT 128 slice, Philips Ingenia MRI $1.5 \mathrm{~T}$, Siemens Magnetom Aera 1.5 T, Siemens Axiom Iconos R200, and Philips DigitalDiagnost.

Different imaging modalities were used to identify the various injuries according to clinical context including X-ray, CT, MRI, and CT angiography. The types of imaging techniques used and the numbers of performed scans are listed in Table 1.

Three hundred twelve X-ray scans of the skull, chest, spine, pelvis, and extremities were performed in 123 patients to spot possible fractures and to detect and locate shrapnel.

One hundred twenty unenhanced CT scans of the brain, facial bones, chest, abdomen, and pelvis were performed in 84 patients to explore internal injuries; post-contrast CT scans were obtained when indicated to evaluate potential complications of these injuries through administration of oral and IV non-ionic contrast. One hundred sixtyeight CT scans of the spine and extremities were also performed in 87 patients for further detailed assessment following X-ray imaging.

CT Scanogram was performed in 6 patients to estimate limb foreshortening as a complication of bone fractures.
Table 1 Types of imaging techniques used to assess injuries and number of performed scans

\begin{tabular}{|c|c|c|}
\hline Imaging techniques & Number & Percentage \\
\hline \multicolumn{3}{|l|}{ X-ray } \\
\hline Skull & 3 & $1.8 \%$ \\
\hline Chest & 27 & $15.8 \%$ \\
\hline Cervical spine & 12 & $7 \%$ \\
\hline Dorsal spine & 6 & $3.5 \%$ \\
\hline Lumbar spine & 6 & $3.5 \%$ \\
\hline Pelvis & 24 & $14 \%$ \\
\hline Shoulder & 39 & $22.8 \%$ \\
\hline Arm & 6 & $3.5 \%$ \\
\hline Elbow & 21 & $12.3 \%$ \\
\hline Forearm & 24 & $14 \%$ \\
\hline Wrist & 18 & $10.5 \%$ \\
\hline Hand & 24 & $14 \%$ \\
\hline Thigh & 27 & $15.8 \%$ \\
\hline Knee & 21 & $12.3 \%$ \\
\hline Leg & 12 & $7 \%$ \\
\hline Ankle & 30 & $17.5 \%$ \\
\hline Foot & 12 & $7 \%$ \\
\hline \multicolumn{3}{|l|}{ CT } \\
\hline Brain & 30 & $17.5 \%$ \\
\hline Maxillofacial & 36 & $21.1 \%$ \\
\hline Chest & 30 & $17.5 \%$ \\
\hline Abdomen \& pelvis & 24 & $14 \%$ \\
\hline Cervical spine & 15 & $8.8 \%$ \\
\hline Dorsal spine & 12 & $7 \%$ \\
\hline Lumbar spine & 18 & $10.5 \%$ \\
\hline Shoulder & 24 & $14 \%$ \\
\hline Elbow & 12 & $7 \%$ \\
\hline Forearm & 9 & $5.3 \%$ \\
\hline Wrist & 18 & $10.5 \%$ \\
\hline Hand & 9 & $5.3 \%$ \\
\hline Bony pelvis & 12 & $7 \%$ \\
\hline Thigh & 6 & $3.5 \%$ \\
\hline Knee & 18 & $10.5 \%$ \\
\hline Ankle & 12 & $7 \%$ \\
\hline Foot & 3 & $1.8 \%$ \\
\hline CT scanogram & 6 & $3.5 \%$ \\
\hline \multicolumn{3}{|l|}{ MRI } \\
\hline Shoulder & 3 & $1.8 \%$ \\
\hline Knee & 6 & $3.5 \%$ \\
\hline Wrist & 3 & $1.8 \%$ \\
\hline \multicolumn{3}{|l|}{ CT angiography } \\
\hline Upper limb & 9 & $5.3 \%$ \\
\hline Lower limb & 6 & $3.5 \%$ \\
\hline
\end{tabular}


MRI scans of the shoulder, knee, and wrist joints were performed in 12 patients without free metallic fragments to depict possible ligament, muscle, or bone marrow injuries.

CT angiography of the upper or lower limb vessels was performed in 15 patients to delineate vascular injuries via injecting $100 \mathrm{ml}$ of non-ionic contrast medium by a pump injector at a rate of $4 \mathrm{ml} / \mathrm{sec}$ through a cannula inserted in the right or left antecubital vein.

\section{Imaging analysis}

Two radiologists independently reviewed each study. In case of discrepancy, studies were re-reviewed and the final decision was reached in consensus.

All scans were analyzed to detect the presence and the site of retained metallic or bullet fragments as well as to assess different organ injuries according to anatomical location. For example, brain scans were assessed for intra-axial or extra-axial hemorrhage, calvarial or skull base fractures, and pneumocephalus. Maxillo-facial scans were examined for facial or orbital fractures, optic nerve or extra-ocular muscle injuries, globe perforation, hemosinus, and surgical emphysema. Chest scans were inspected for chest wall fractures, lung contusions or lacerations, pleural effusion, pneumothorax, pneumomediastinum, and surgical emphysema. Abdominal scans were evaluated for solid or hollow organ injury, hemoperitoneum, retroperitoneal hematoma, abdominal wall hematoma, and pneumoperitoneum, as well as possible associated complications (e.g., superadded infection). Spine and extremities scans were checked for fractures and potential associated muscle or ligament injury. Angiography scans were reviewed for vascular stenosis, occlusion, transection, or dissection.

\section{Statistical analysis}

The collected data were tabulated and introduced to a personal computer using "Microsoft Office Excel Software" program (2016) for Windows. All results were described as frequency and percentage. No complex statistical analysis was required.

\section{Results}

This study included 171 male patients presented to the 3 Egyptian tertiary hospitals with a history of exposure to blast or firearm combat-related injuries. The imaging findings of their injuries are reported in Table 2.

In $84(49.1 \%)$ patients, metallic foreign bodies were detected in different locations including intra-cranially, while in $21(12.3 \%)$ patients, bullets were identified lodged in the lungs, intra-peritoneal, within the ethmoidal sinus (Fig. 1a), embedded at the para-vertebral muscles and at the subcutaneous tissue.
Table 2 Imaging findings of conflict-related injuries encountered in our study population

\begin{tabular}{|c|c|c|}
\hline Imaging findings & Number & Percentage \\
\hline Cranial injuries & 53 & $31 \%$ \\
\hline Cerebral contusion & 8 & $4.7 \%$ \\
\hline Calvarial fracture & 9 & $5.3 \%$ \\
\hline Skull base fracture & 3 & $1.8 \%$ \\
\hline Subdural hematoma & 11 & $6.4 \%$ \\
\hline Subgaleal hematoma & 16 & $9.4 \%$ \\
\hline Encephalomalacia & 2 & $1.2 \%$ \\
\hline Pneumocephalus & 4 & $2.3 \%$ \\
\hline Maxillofacial injuries & 70 & $41 \%$ \\
\hline Nasal bone fractures & 15 & $8.8 \%$ \\
\hline Zygomatic fracture & 2 & $1.2 \%$ \\
\hline Maxillary fracture & 3 & $1.8 \%$ \\
\hline Orbital fracture & 6 & $3.5 \%$ \\
\hline Globe rupture & 12 & $7 \%$ \\
\hline Hemosinus & 4 & $2.3 \%$ \\
\hline Soft tissue edema & 23 & $13.5 \%$ \\
\hline Surgical emphysema & 5 & $2.9 \%$ \\
\hline Thoracic injuries & 55 & $32.1 \%$ \\
\hline Chest wall fractures & 21 & $12.3 \%$ \\
\hline Lung contusion/laceration & 12 & $7 \%$ \\
\hline Pleural effusion & 6 & $3.5 \%$ \\
\hline Pneumothorax & 9 & $5.3 \%$ \\
\hline Surgical emphysema & 7 & $4.1 \%$ \\
\hline Abdominal injuries & 36 & $21.1 \%$ \\
\hline Solid organ injury & 12 (9 liver-3 renal) & $7 \%$ \\
\hline Bowel perforation & 3 & $1.8 \%$ \\
\hline Hemoperitoneum & 9 & $5.3 \%$ \\
\hline Retroperitoneal hematoma & 4 & $2.3 \%$ \\
\hline Abdominal wall hematoma & 2 & $1.2 \%$ \\
\hline Surgical emphysema & 5 & $2.9 \%$ \\
\hline Abscess formation & 1 & $0.6 \%$ \\
\hline \multicolumn{3}{|l|}{ Spine injuries } \\
\hline Fractures & 15 & $8.8 \%$ \\
\hline Extremity injuries & 132 & $77.2 \%$ \\
\hline Upper limb fractures & 69 & $40.4 \%$ \\
\hline Lower limb fractures & 48 & $28.1 \%$ \\
\hline Muscle injury & 6 & $3.5 \%$ \\
\hline Ligament injury & 3 & $1.8 \%$ \\
\hline Marrow contusion & 6 & $3.5 \%$ \\
\hline \multicolumn{3}{|l|}{ CT scanogram } \\
\hline Foreshortening & 6 & $3.5 \%$ \\
\hline \multicolumn{3}{|l|}{ Vascular injuries } \\
\hline Vascular occlusion & 8 & $4.7 \%$ \\
\hline
\end{tabular}




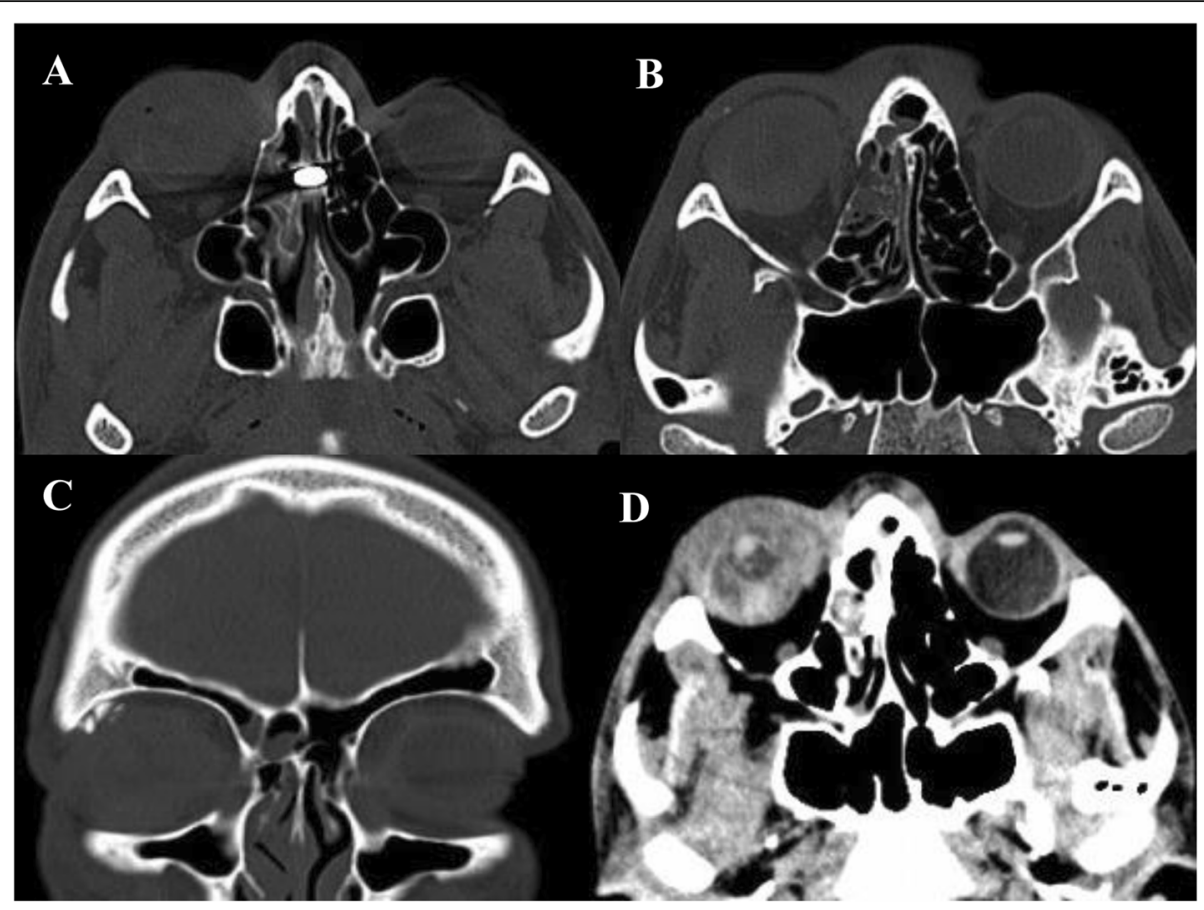

Fig. 1 CT scan of the facial bones of a 22-year-old male. a, b Axial bone window showing a bullet at the ethmoidal air cells and right medial orbital wall fracture associated with hemosinus. c Coronal bone window showing right medial orbital wall fracture and intra-orbital shrapnel. d Axial soft tissue window showing ruptured right eye globe with vitreous hemorrhage

Brain scans showed evidence of cranial injuries in $53(31 \%)$ of patients in the form of either early injuries, e.g., hemorrhage, or late injuries, e.g., encephalomalacia (Fig. 2).

Maxillo-facial injuries were depicted in 70 (41\%) of patients; most commonly in the form of facial or orbital bone fractures and most seriously in the form of globe rupture. Associated injuries were also depicted, e.g., hemosinus (Fig. 1).

In chest scans, chest wall fractures were the most commonly observed injury (Fig. 3a), followed by lung contusion or laceration and pneumothorax (Fig. $3 \mathrm{c}$ and $\mathrm{d}$ ).

Reviewing abdominal scans revealed solid organ injuries $(n=12,7 \%)$ to be the most common combat-related abdominal injury, more frequently involving the liver $(n=9,5.3 \%)$ (Fig. 3a, and b), followed by the kidneys $(n=$ $3,1.8 \%$ ), Associated late complications, e.g., intramuscular abscess formation (Fig. 4a, and b) were also detected.

Spinal fractures were recognized in $15(8.8 \%)$ patients (Fig. 4c), upper limb fractures in 69 (40.4\%) of patients

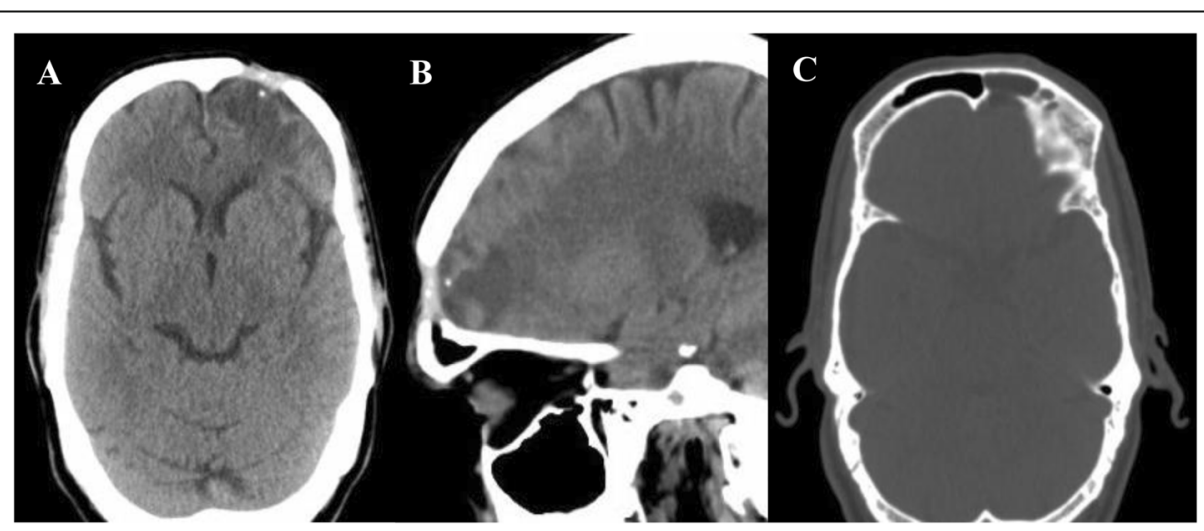

Fig. 2 CT scan of the brain of a 43-year-old male. a Axial and $\mathbf{b}$ sagittal soft tissue window showing left frontal bone fracture with underlying shrapnel and encephalomalacia. c Axial bone window showing associated left frontal hemosinus 


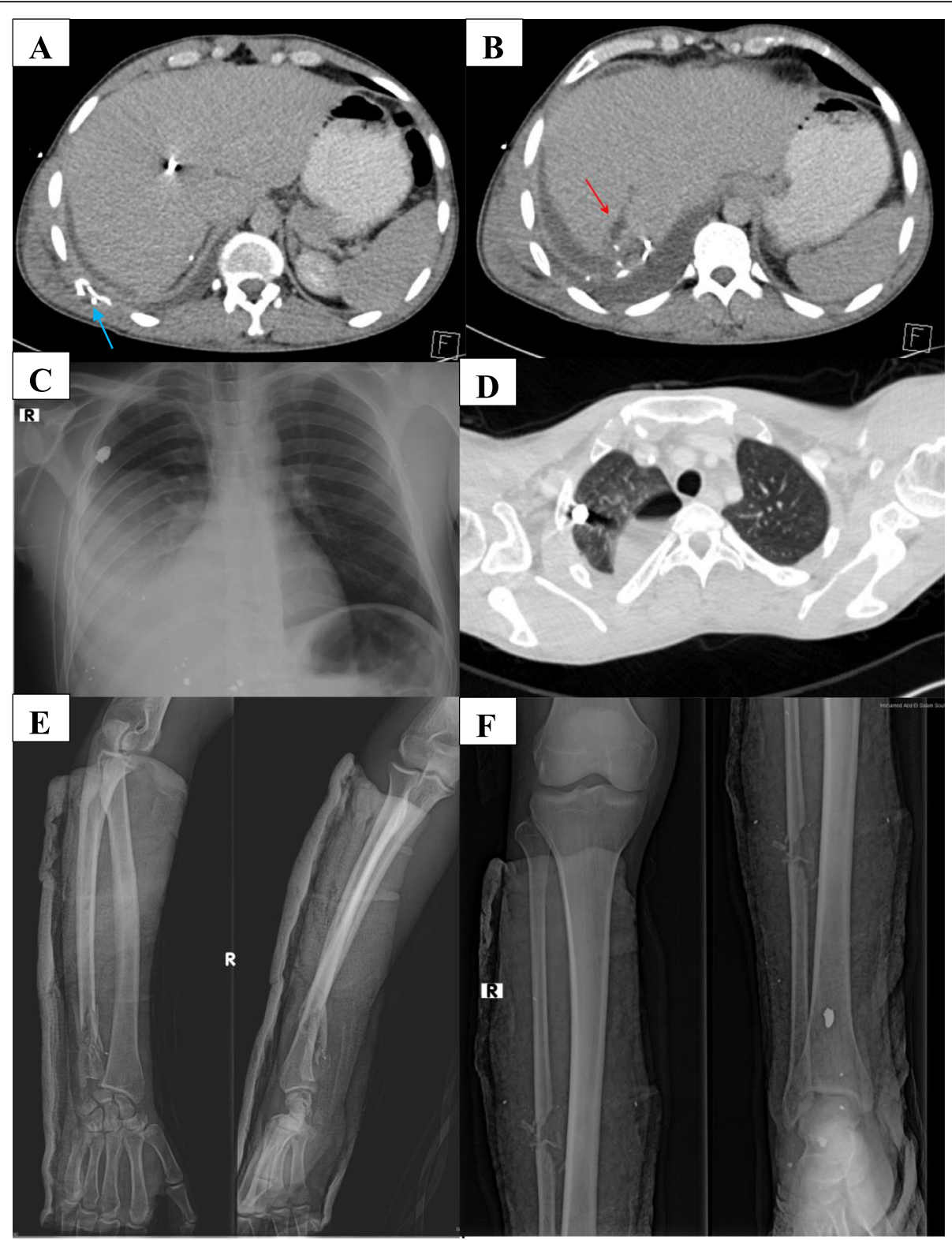

Fig. 3 Male patient 30 years old. a, b Axial contrast-enhanced $C T$ of the abdomen showing a bullet at the hepatic dome and shrapnel at the right diaphragmatic copula associated with comminuted fracture of the right 10th rib (blue arrow), liver laceration (red arrow), and subcapsular hematoma. $\mathbf{c}$ Chest $\mathrm{X}$-ray posteroanterior view and $\mathbf{d} \mathrm{CT}$ chest axial lung window of the same patient showing a bullet at the right lung apex associated with hydro-pneumothorax. e Right forearm X-ray of the same patient in posteroanterior (left) and lateral (right) views showing comminuted fracture of the distal ulna. $\mathbf{f}$ Right leg X-ray of the same patient in antero-posterior view showing comminuted fracture of the fibular shaft and shrapnel

(Figs. 3e and 5), and lower limb fractures in 48 (28.1\%) of patients (Fig. 3f), making fractures the most frequent combat-related injury by far. Associated injuries, e.g., muscle injury (Fig. 6), were also encountered.

In $8(4.7 \%)$ patients, vascular abnormalities were identified in the form of abrupt vascular occlusions (Fig. 7), while metallic fragments with no related vascular abnormalities were detected in 7 (4.1\%) patients.

\section{Discussion}

Over the past few years, our Egyptian tertiary hospitals have received many injured patients from nearby countries where wars are rising.

The ongoing conflicts in these countries do not only impact military personnel, but also have an immeasurable effect on the civilian population. Since many hospitals across these countries have been hit and are now 


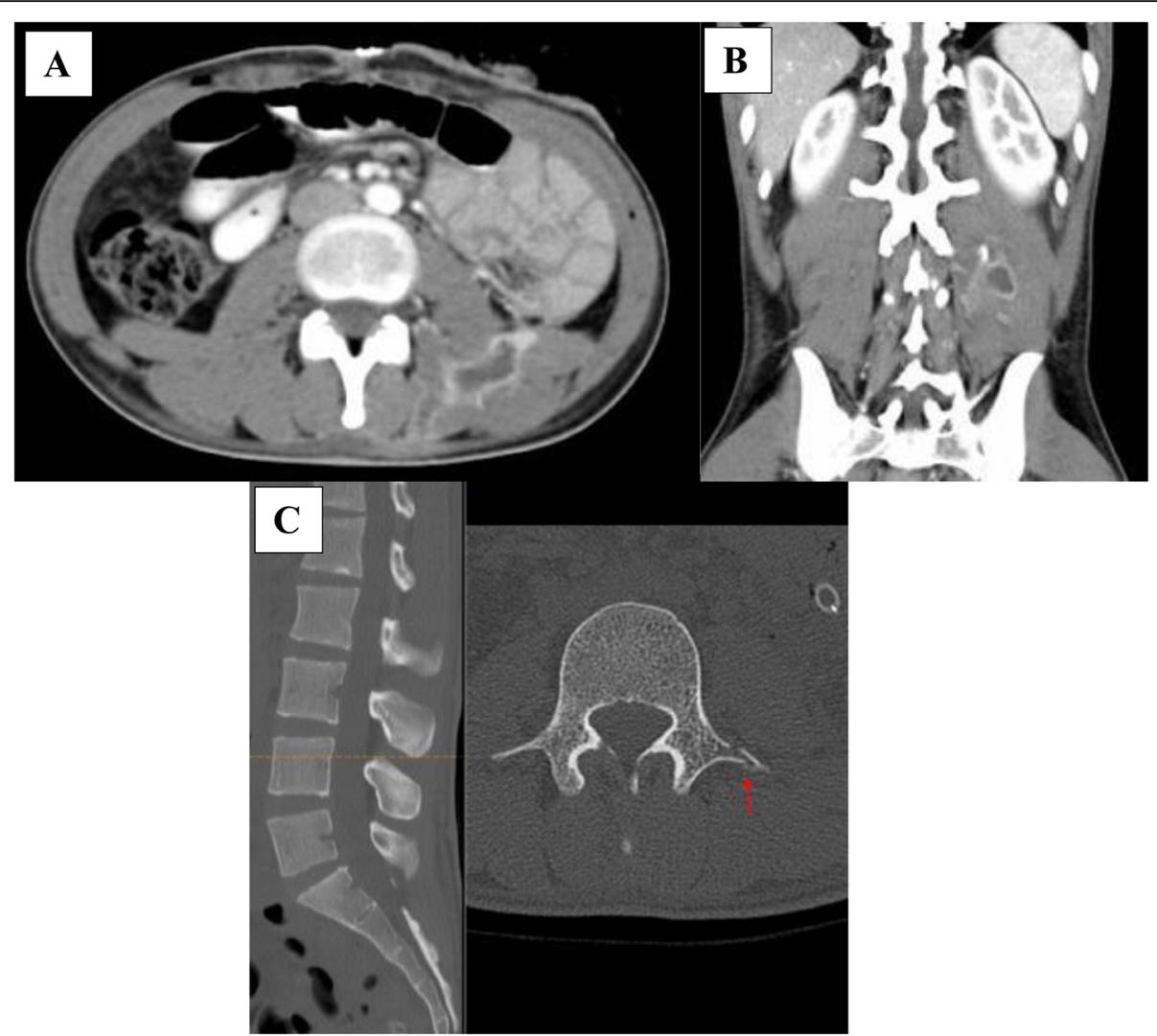

Fig. 4 Male patient 23 years old. a Axial and $\mathbf{b}$ coronal contrast-enhanced $C T$ of the abdomen showing marginally enhancing intra-muscular abscess at the left back muscles. c Sagittal (left) and axial (right) CT bone window of the lumbar spine of the same patient showing fracture of $L 4$ left transverse process (red arrow)

semi-functional or destroyed [4], patients are transferred to more secure and more efficiently equipped nearby countries, such as Egypt.

Being a rising subject in the last few years, only a few researchers studied the firearm and missile injuries in conflict zones; either focusing on the cranial and maxillofacial injuries as in Pabuscu et al. study [5] or describing the types and patterns of injuries as in Wild et al. study [2], yet, not from a radiological point of view as in our study.

Our role as radiologists is to determine the exact sites and types of combat-related injuries, the associated soft tissue, bone, or vascular injuries, as well as the possible delayed or postoperative complications.

According to the study conducted by Wild et al., patients with conflict-related injuries were predominantly males, and most of them were of young age with a mean age of 26 years [2].

Also, Bodalal and Mansor found that the incidence rates of gunshot injuries indicate strong male predilection with males being over 20 times more likely to be shot during the war than females and that the average age of gunshot patients was 28.32 years [6].

This was more or less consistent with our study in which all patients were males with a mean age of 28.9 years.

In Pabuscu et al. study, bullets and metallic foreign bodies were identified in $70.7 \%$ of patients wounded by gunshots and fragmentation bombs [5], whereas in our study, $61.4 \%$ of patients displayed bullets and metallic foreign bodies of different sizes and shapes in different locations of the body, but in the remaining $38.6 \%$, the bullet or the metallic fragments did not lodge in the patients' bodies.

Wild et al. stated that the extremities were the most common anatomical regions involved by combat-related injuries composing $33.5 \%$ of them, followed by head and neck injuries in $18 \%$, and soft tissue wounds in $14 \%$, while thoracic and abdominal injuries were less common and accounted for 10.4 and $7.5 \%$, respectively [2].

Similarly, Bodalal and Mansor declared that $68.9 \%$ of gunshot injuries occurred in the limbs with the lower 


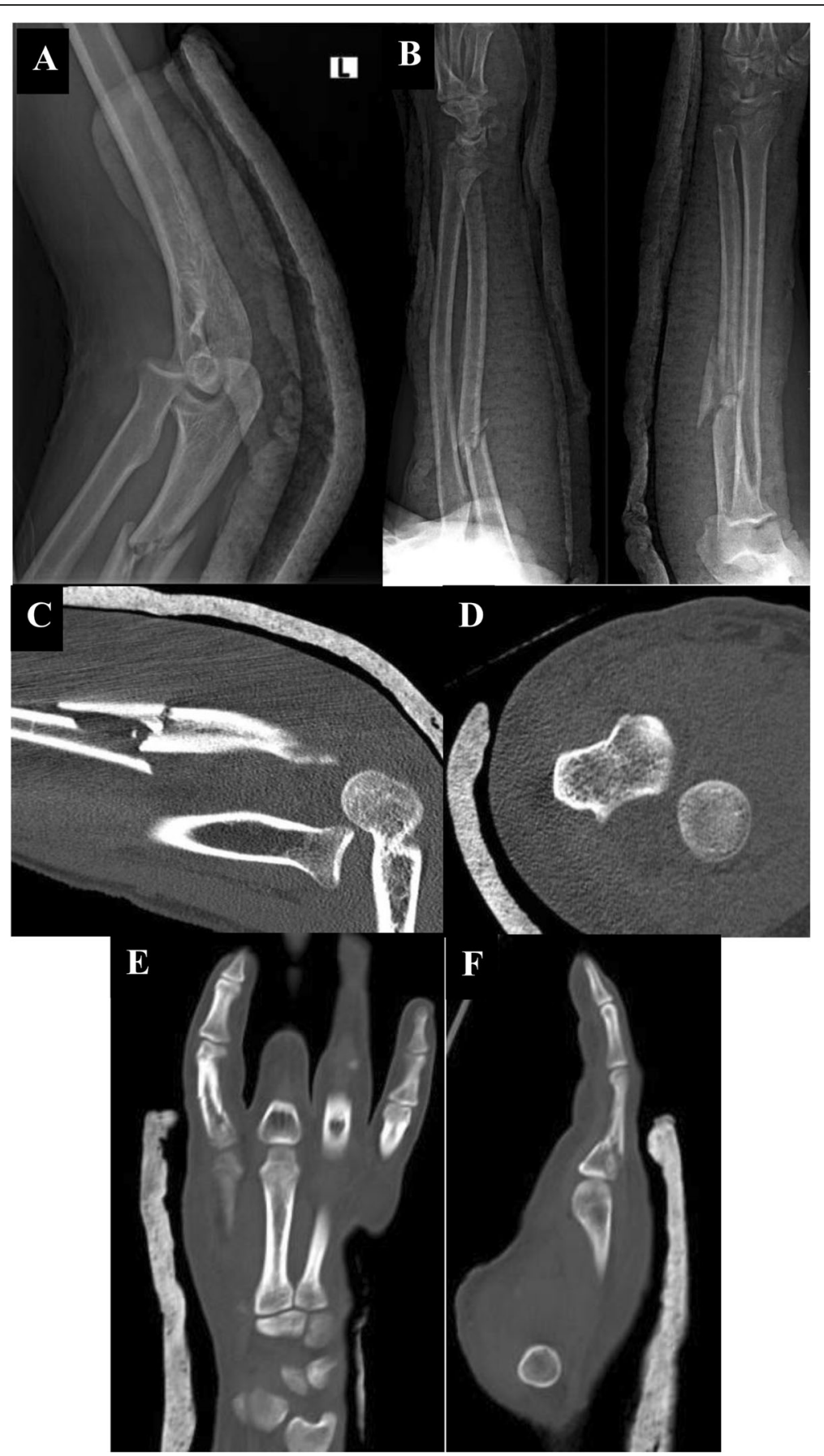

Fig. 5 Male patient 25 years old. a Left elbow X-ray lateral view, b left forearm X-ray posteroanterior (right) and lateral (left) views, c sagittal, and d axial CT bone window of the left elbow showing anterior dislocation of the left radial head and left ulnar shaft comminuted fracture. e Coronal and $\mathbf{f}$ sagittal CT bone window of the left hand of the same patient showing left index finger proximal phalanx comminuted fracture

limbs most commonly affected, followed by the upper limbs and the chest [6].

In concordance with these studies, injuries involving the musculoskeletal system of the extremities were the most frequent in our patients representing about $77.2 \%$, followed by maxillofacial injuries in $41 \%$, chest injuries in $32.1 \%$, cranial injuries in $31 \%$, and abdominal injuries in $21.1 \%$ of patients.

Among the extremity injuries, fractures were the most common comprising about $68.5 \%$. In fact, bone fractures were by far the most prevailing type of injury across all systems in our study as upper limb fractures were 


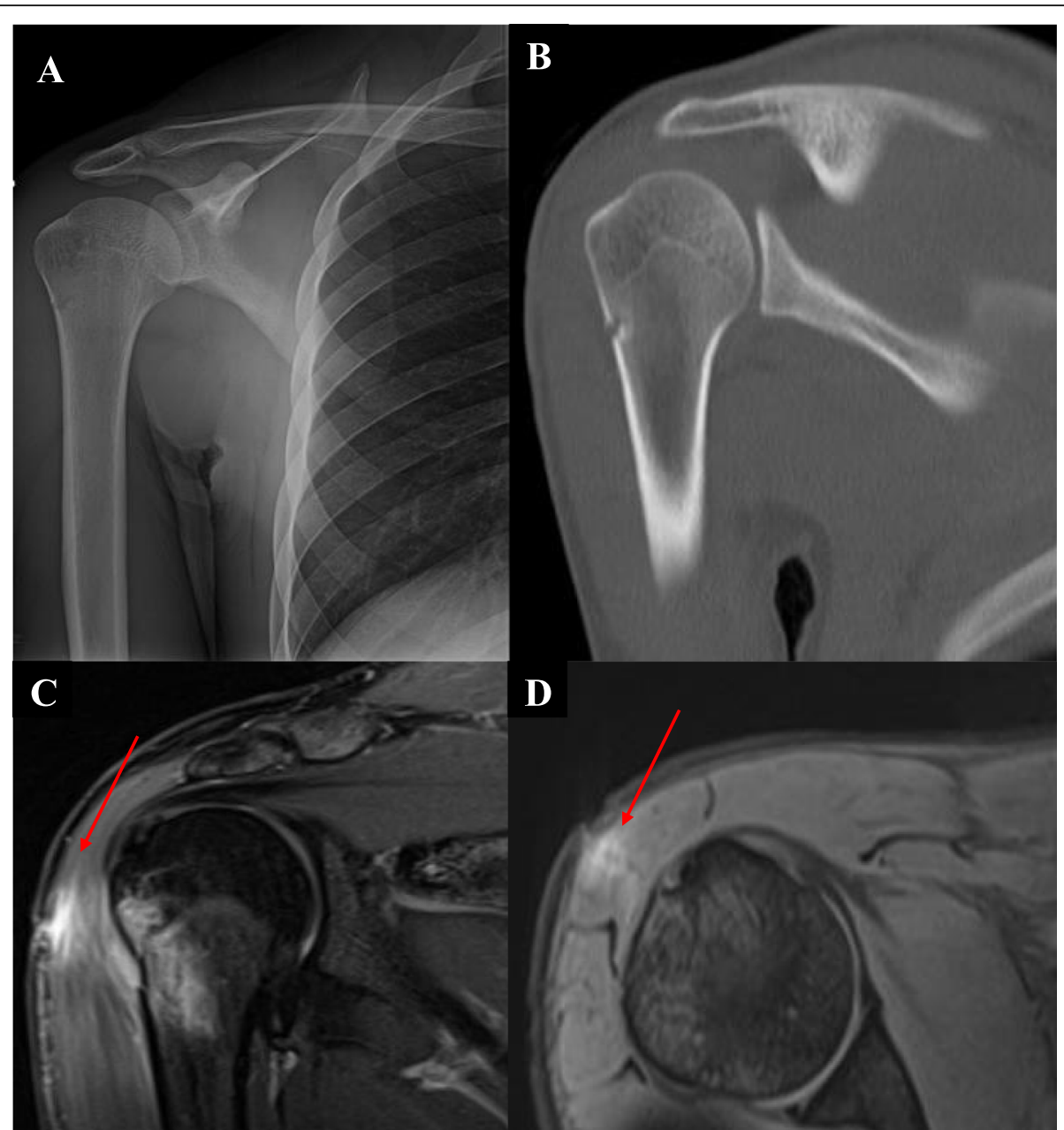

Fig. 6 Male patient 22 years old. a X-ray anteroposterior view and $\mathbf{b}$ coronal $C T$ bone window of the right shoulder showing proximal right humeral shaft fracture. $\mathbf{c}$ Coronal STIR and $\mathbf{d}$ axial gradient of the right shoulder of the same patient also showing the proximal right humeral shaft fracture with surrounding bone marrow edema and associated deltoid muscle partial tear (red arrows)

encountered in 69 (40.4\%), lower limb fractures in 48 (28.1\%), maxillo-facial fractures in $26(15.2 \%)$, spinal fractures in $15(8.8 \%)$, chest wall fractures in $21(2.3 \%)$, and calvarial fractures in 9 (5.3\%) patients.

Comparing combat-related civilian injuries to military personnel injuries from literature revealed similar injury patterns between the two groups, as the consensus through current war trauma literature is that between 65 and $70 \%$ of war wounds involve the musculoskeletal system [7]. Also, Cameron and Owens state that the burden of musculoskeletal combat-related wounds in military personnel is very high with extremity wounds representing $54 \%$ of all wounds [8].

Likewise, Griffiths and Clasper declare that $70 \%$ of all wounds encountered during combat induced by various mechanisms such as bomb blasts and bullets affect the extremities with the lower limb predominantly affected [9].
In addition, Chandler et al. 2017 found that combat injuries more commonly involve the extremities than other body parts with fractures being the most frequently recorded injury and the lower limbs the most frequently involved site [10].

Similarly, Maričević and Erceg described the highest percentage of all combat injuries to the extremities accounting for $75 \%$ with bone fractures seen in $62 \%$ of the patients and the lower extremities the most commonly involved [11].

Although in Bodalal and Mansor study vascular lesions were very common, they were the least frequent type of injury in our study detected only in $4.7 \%$ of patients [6].

However, this was in similarity to military injuries described by Maričević and Erceg showing that gunshot wounds and fractures were relatively rarely associated with vascular injuries, although soft tissue wounds were frequently present [11]. 

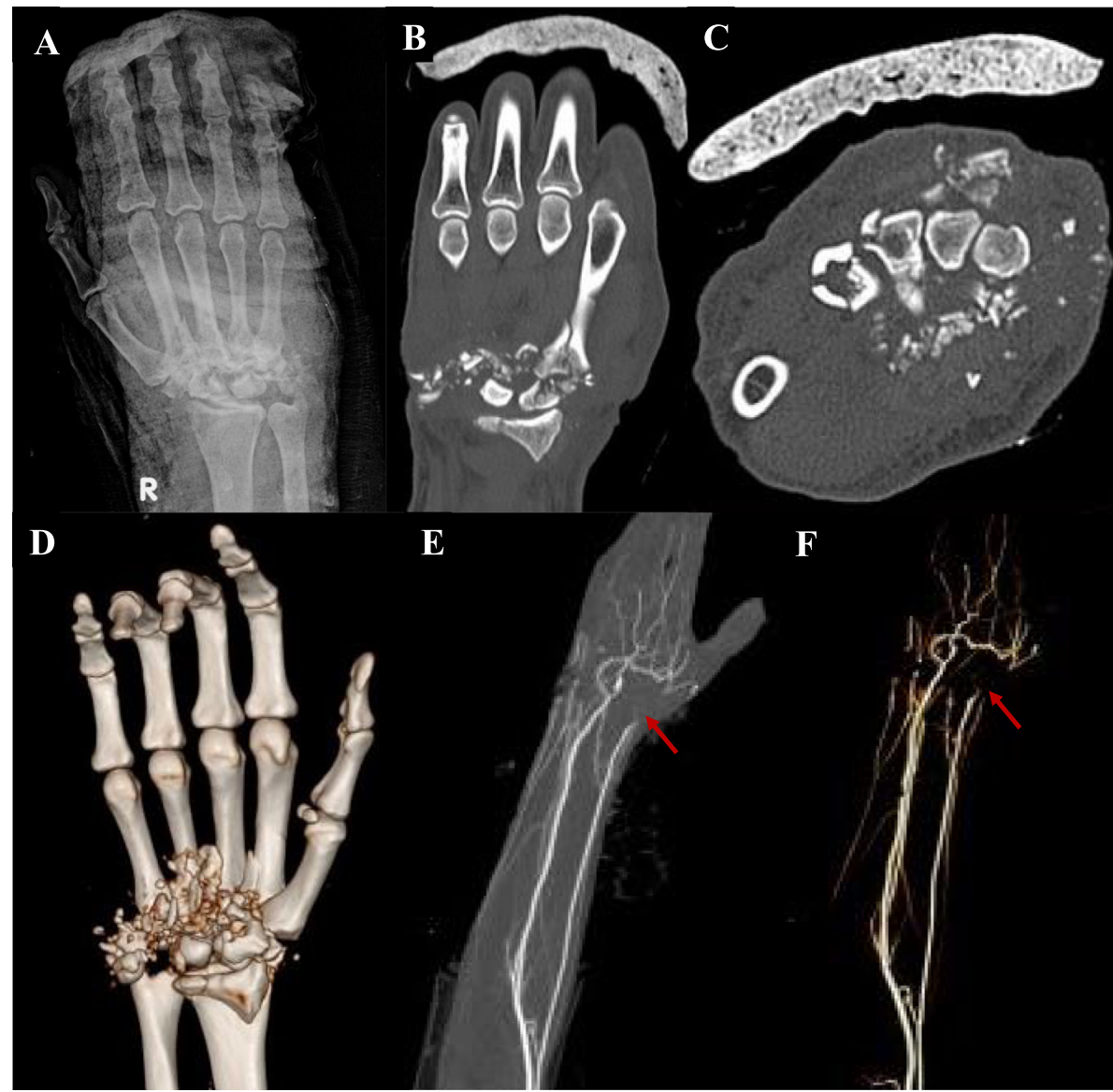

Fig. 7 Male patient 34 years old. a X-ray posteroanterior view, b coronal CT bone window, c axial CT bone window, and $\mathbf{d}$ three-dimensional reconstruction CT image of the right wrist showing comminuted fractures of all carpal bones, distal radius, and base of the second metacarpal bone. $C T$ angiography of the right upper limb of the same patient in $\mathbf{e}$ maximum intensity projection and $\mathbf{f}$ three-dimensional reconstruction image showing total occlusion of the right distal radial artery (red arrows).

\section{Conclusion}

In conclusion, radiological assessment aids in the evaluation of patients coming from conflict zones pre- and postoperatively to recognize the precise sites and types of their injuries, the number and location of metallic shrapnel or bullets, and detection of possible associated complications, which aid in accurate demonstration of the extent and patterns of combat-related injuries and guide the management plan.

\section{Acknowledgements}

Not applicable.

\section{Authors' contribution}

SFT and MNG reviewed the images. SFT and IHI analyzed and interpreted the patient data. SFT and MNG wrote the manuscript and $I H \|$ reviewed it. The authors have read and approved the manuscript.
Availability of data and materials

The datasets used and/or analyzed during the current study are available from the corresponding author on reasonable request.

\section{Declarations}

Ethics approval and consent to participate

Approval of the ethical committee of the "Radiology department, Faculty of Medicine, Cairo University" was granted before conducting this prospective study; Reference number: not applicable.

Local institutional review board approval was granted before conducting this cross-sectional study, and written informed consent was obtained from all patients.

\section{Consent for publication}

All patients included in this research gave written informed consent to publish the data contained within this study. If the patients were less than 16 years old, deceased, or unconscious when consent for publication was requested, written informed consent for the publication of this data was given by their parents or legal guardians.

The authors declare that they have no competing interests.

\section{Funding}

The authors state that this work has not received any funding. 
Received: 17 February 2021 Accepted: 6 May 2021

Published online: 17 May 2021

\section{References}

1. Daw MA, El-Bouzedi AH, Dau AA (2019) Trends and patterns of deaths, injuries and intentional disabilities within the Libyan armed conflict: 2012-2017. PLoS One 14(5):e0216061. https://doi.org/10.1371/journal.pone.0216061

2. Wild H, Stewart BT, LeBoa C, Stave CD, Wren SM (2020) Epidemiology of injuries sustained by civilians and local combatants in contemporary armed conflict: an appeal for a shared trauma registry among humanitarian actors. World J Surg 44:1-11

3. Fares J, Khachfe H, Fares M, Salhab H, Fares Y (2020) Conflict medicine in the Arab world. In: Handbook of healthcare in the Arab World. Springer, Cham

4. Corcione A, Petrini F, Gristina G, De Robertis E (2017) A statement on the war in Syria from SIAARTI and partners. Lancet 389(10064):31. https://doi. org/10.1016/50140-6736(16)32593-4

5. Pabuscu Y, Bulakbasi N, Kocaoğlu M, Üstünsöz B, Tayfun C (2003) A different approach to missile induced head injuries. Comput Med Imaging Graph 27(5):397-409. https://doi.org/10.1016/50895-6111(03)00015-6

6. Bodalal Z, Mansor S (2013) Gunshot injuries in Benghazi-Libya in 2011: the Libyan conflict and beyond. Surgeon 11(5):258-263. https://doi.org/10.1016/ j.surge.2013.05.004

7. Ng C, Mifsud M, Borg JN, Mizzi C (2015) The Libyan civil conflict: selected case series of orthopaedic trauma managed in Malta in 2014. Scand J Trauma Resusc Emerg Med 23(1):103

8. Cameron $\mathrm{KL}$, Owens BD (2016) Musculoskeletal injuries in the military. Springer, New York. https://doi.org/10.1007/978-1-4939-2984-9

9. Griffiths D, Clasper J (2006) (iii) Military limb injuries/ballistic fractures. Curr Orthop 20(5):346-353. https://doi.org/10.1016/j.cuor.2006.07.007

10. Chandler H, MacLeod K, Penn-Barwell JG, Penn-Barwell JG, Bennett PM, Fries CA, Kendrew JM, Midwinter M, Bishop J, Rickard RF, Sargeant ID, Porter K, Rowland T, Mountain A, Kay A, Mortiboy D, Stevenson T, Myatt RM (2017) Extremity injuries sustained by the UK military in the Iraq and Afghanistan conflicts: 2003-2014. Injury 48(7):1439-1443. https://doi.org/10.1016/j.injury.2 017.05.022

11. Maričević A, Erceg M (1997) War injuries to the extremities. Mil Med 162(12): 808-811. https://doi.org/10.1093/milmed/162.12.808

\section{Publisher's Note}

Springer Nature remains neutral with regard to jurisdictional claims in published maps and institutional affiliations.

\section{Submit your manuscript to a SpringerOpen ${ }^{\circ}$ journal and benefit from:}

- Convenient online submission

- Rigorous peer review

- Open access: articles freely available online

- High visibility within the field

- Retaining the copyright to your article

Submit your next manuscript at $\boldsymbol{\nabla}$ springeropen.com 